\title{
Energy balances, greenhouse gas emissions and economics of biochar production from palm oil empty fruit bunches
}

\begin{abstract}
This paper presents results from a gate-to-gate analysis of the energy balance, greenhouse gas (GHG) emissions and economic efficiency of biochar production from palm oil empty fruit bunches (EFB). The analysis is based on data obtained from EFB combustion in a slow pyrolysis plant in Selangor, Malaysia. The outputs of the slow pyrolysis plant are biochar, syngas, bio-oil and water vapor. The net energy yield of the biochar produced in the Selangor plant is $11.47 \mathrm{MJ} \mathrm{kg-1} \mathrm{EFB}$. The energy content of the biochar produced is higher than the energy required for producing the biochar, i.e. the energy balance of biochar production is positive. The combustion of EFB using diesel fuel has the largest energy demand of $2.31 \mathrm{MJ}$ $\mathrm{kg}-1 \mathrm{EFB}$ in the pyrolysis process. Comparatively smaller amounts of energy are required as electricity (0.39 MJ kg-1 EFB) and for transportation of biochar to the warehouse and the field $(0.13 \mathrm{MJ} \mathrm{kg-1}$ EFB). The net greenhouse gas emissions of the studied biochar production account for $0.046 \mathrm{~kg}$ CO2-equiv. $\mathrm{kg}-1 \mathrm{EFB} \mathrm{yr}-1$ without considering fertilizer substitution effects and carbon accumulation from biochar in the soil. The studied biochar production is profitable where biochar can be sold for at least 533 US- $\$ \mathrm{t}-1$. Potential measures for improvement are discussed, including higher productivity of biochar production, reduced energy consumption and efficient use of the byproducts from the slow pyrolysis.
\end{abstract}

Keyword: Biochar; Empty fruit bunches; Palm oil; Greenhouse gas emissions; Energy balances; Economic assessment 